\title{
Modelling the Height of Hydrothermally Synthesized Titanium Dioxide Nanostructures
}

\author{
Alka Jaggessar ${ }^{1,2}$, Prasad KDV Yarlagadda ${ }^{1,2, *}$ \\ ${ }^{1}$ School of Mechanical, Medical and Process Engineering, Science and Engineering Faculty, Queensland University of \\ Technology, 2 George Street, Brisbane, 4000, Australia \\ ${ }^{2}$ Institute of Health and Biomedical Innovation, Queensland University of Technology, 60 Musk Avenue, Kelvin Grove, \\ 4056, Australia
}

*Corresponding author: E-mail: y.prasad@qut.edu.au; Tel.: (+61) 731385167

DOI: $10.5185 /$ amlett.2020.061529

Bacterial infection is a widespread concern for the medical community. With the rise of antibiotic resistant bacteria strains, research has begun to focus on developing bactericidal surfaces as a method of infection control, to reduce society's dependence on antibiotics. Previous work in this area has established hydrothermal synthesis as an effective method of fabricating bactericidal titanium dioxide nanostructures, with structure height statistically correlated to bactericidal efficiency. This study investigates the effect of $\mathrm{NaOH}$ concentration, reaction temperature and reaction time on hydrothermally synthesized $\mathrm{TiO}_{2}$ nanostructures. Various $\mathrm{TiO}_{2}$ nanostructured surfaces, morphologies and dimensions were achieved by altering hydrothermal process conditions. This data was used to develop 3 models to predict nanostructure height, as a function of hydrothermal fabrication conditions. The three models are qualitatively validated using statistical data. These models provide a preliminary basis of modelling $\mathrm{TiO}_{2}$ nanostructure growth during hydrothermal synthesis. The findings of this study are significant for the designing of nanostructured surfaces for antibacterial applications, and users of the hydrothermal method for effective and efficient nanostructure fabrication.

\section{Introduction}

Bactericidal nanotextured surfaces have become a significant area of research interest in recent years. Studies propose that the naturally occurring micro and nanostructures found on certain plant and animal species result in antibacterial and anti-biofouling behavior [1-7]. Since the discovery of these properties, researchers have attempted to recreate this effect using metallic and polymer materials $[\mathbf{1 , 8 - 1 6}]$. Hydrothermal synthesis has been used in a range of studies $[8,13,16,17]$ due to its reliability, environmentally friendly nature, simplicity, low cost compared to other methods, and flexibility for material morphology control $[\mathbf{1 3 , 1 7}]$. The process is effective at producing various morphologies, such as nanoparticles, nanorods, nanowires and nanotubes.

Researchers believe there are a several surface properties that influence bactericidal efficiency, such as wettability $[\mathbf{1 , 9 , 1 8 - 2 0}]$, and structure height, diameter and density [21-23]. In our previous work, nanostructure height was statistically correlated to bactericidal efficiency of hydrothermally nanostructured $\mathrm{TiO}_{2}$ against both Gramnegative and Gram-positive bacteria [24]. From this finding, it is important to predict nanostructure growth during hydrothermal synthesis.

The morphology of hydrothermally synthesized structures is a result of several factors. Adjusting precursor concentration, solvent composition, solvent $\mathrm{pH}$, operation temperature and reaction duration, alters nanoparticle shape, size and surface roughness [25-28]. High precursor concentration generally influences morphology and increases structure density (forming closely packed arrays) and diameter [29]. Similarly, long reaction time produces large particles $[\mathbf{3 0 , 3 1}]$, with similar effects seen above $180^{\circ} \mathrm{C}$. While these patterns and behaviors have been qualitatively investigated, quantitative modelling is lacking.

Currently, statistical modelling involving the hydrothermal process is limited to thermodynamic and kinetic modelling. Phase stability and yield diagrams allow control over chemical phases formed during reactions, and are functions of $\mathrm{pH}$, temperature and initial concentration. The original model was proposed by Lencka et al. (1993), and was developed and validated using barium titanate $\left(\mathrm{BaTiO}_{3}\right)$ and lead titanate $\left(\mathrm{PbTiO}_{3}\right)$ [32]. This has been expanded to yield diagrams for other compounds such as $\mathrm{BaWO}_{4}[\mathbf{3 3}]$ and $\mathrm{PbTiO}_{3}$, with a tetramethylammonium hydroxide mineralizer [34]. These diagrams however are only applicable to the hydrothermal synthesis of ceramic powders [35], and cannot be applied to nanostructure growth on metallic substrates. Researchers have not yet developed a model describing the height of hydrothermally synthesized structures as a function of hydrothermal process conditions. This study develops statistical models 


\section{Advanced Materials Letters www. vbripress.com/aml}

between nanostructure height and $\mathrm{NaOH}$ concentration, reaction temperature and reaction duration. Quantitative representation of hydrothermal growth is important to the hydrothermal process, working to improve process efficiency and predict resulting material properties prior to fabrication.

\section{Experimental}

Nanotextured $\mathrm{TiO}_{2}$ surfaces were fabricated using hydrothermal synthesis. Various surface textures and heights were achieved by altering $\mathrm{NaOH}$ concentration, reaction time and reaction temperature. $\mathrm{NaOH}$ concentration ranged from $0.1-2.0 \mathrm{M}$, reaction time from $1-10$ hours and reaction temperature from $120-240^{\circ} \mathrm{C}$. The temperature range was dictated by process constraints. Hydrothermal structures only grow above $100^{\circ} \mathrm{C}[31$, while the hydrothermal vessel cannot exceed $240^{\circ} \mathrm{C}$, as per manufacturer and safety instructions. Reaction time and $\mathrm{NaOH}$ concentration ranges were selected using previous trial and error experimentation.

\section{Material synthesis}

$\mathrm{TiO}_{2}$ micro and nanostructures were fabricated on $1 \mathrm{~cm}^{2}$ titanium substrates, which were polished to a surface roughness of $0.04 \mu \mathrm{m}$ (mirror shine). Plates were sonicated in acetone for 10 minutes, rinsed 3 times with $18.2 \mathrm{M} \Omega$ $\mathrm{H}_{2} \mathrm{O}$, and dried with $\mathrm{N}_{2}$ gas. Samples were inserted into a custom-made PTFE holder and put into a $125 \mathrm{~mL}$ Parr acid digestion vessel, with $60 \mathrm{~mL} \mathrm{NaOH}$ (see Table 1 for processing conditions). The vessel was placed in the oven, and heated to the specified reaction temperature. The vessel was removed after the given reaction time and cooled to room temperature. Individual samples were then rinsed 3 times in $18.2 \mathrm{M} \Omega \mathrm{H}_{2} \mathrm{O}$ and dried with $\mathrm{N}_{2}$ gas. Samples were annealed for 1 hour at $300^{\circ} \mathrm{C}\left(10^{\circ} \mathrm{C} / \mathrm{min}\right.$ heating rate), and removed when the furnace temperature had cooled below $80^{\circ} \mathrm{C}$. Once at room temperature, samples were submerged in $20 \mathrm{~mL}$ of $0.6 \mathrm{M} \mathrm{HCl}$ solution for 30 minutes. Samples were rinsed 3 times in $18.2 \mathrm{M} \Omega \mathrm{H}_{2} \mathrm{O}$ and dried with $\mathrm{N}_{2}$ gas. Finally, samples were calcined for 2 hours at $600^{\circ} \mathrm{C}$ $\left(10^{\circ} \mathrm{C} / \mathrm{min}\right.$ heating rate $)$ and left to cool in the furnace until furnace temperature reached $80^{\circ} \mathrm{C}$. Three samples were fabricated for each condition.

\section{Structure measurements}

The JEOL JSM-7001F Scanning Electron Microscope (SEM) was used to measure the structure height of 10 randomly selected structures from each sample, giving a total of 30 height measurements per hydrothermal condition. Structure heights were measured using in-built JEOL software and was defined as the length from the base to the tip of the structure (excluding substrate thickness).

\section{Statistical modelling}

IBM SPSS Statistics was used to develop statistical models in this work. Values for nanostructure height, $\mathrm{NaOH}$ concentration, reaction time and reaction temperature were normalized by dividing each measured value by the lowest recorded value in the data set. Descriptive Statistics (scatterplots, means, medians and data normality) were initially used to investigate the nature of the data. The relationship between height and each individual normalized parameter $\left(\mathrm{NaOH}\right.$ concentration $\left(C^{*}\right)$, reaction time $\left(t^{*}\right)$ and reaction temperature $\left(T^{*}\right)$ ) was established through univariate regression. Insignificant terms $(p>0.05)$ were removed to improve model accuracy. Quantitative statistical data from the model, such as residual data, skewness and kurtosis were examined for model accuracy. To optimize accuracy, all 30 height measurements were included in the model, allowing the model to include measurement variance.

Table 1. Hydrothermal process conditions.

\begin{tabular}{|c|c|c|c|}
\hline $\begin{array}{c}\text { Samples for } \\
\text { Concentration } \\
\text { Model } \\
\end{array}$ & $\begin{array}{c}\mathrm{NaOH} \\
\text { Concentration } \\
\text { (M) } \\
\end{array}$ & $\begin{array}{c}\text { Reaction } \\
\text { Temperature } \\
\left({ }^{\circ} \mathbf{C}\right) \\
\end{array}$ & $\begin{array}{c}\text { Reaction } \\
\text { Time } \\
\text { (Hrs) }\end{array}$ \\
\hline $0.1 \_3 \_240$ & 0.1 & 3 & 240 \\
\hline $0.25 \_3 \_240$ & 0.25 & 3 & 240 \\
\hline $0.5 \_3 \_240$ & 0.5 & 3 & 240 \\
\hline $1.0 \_3 \_240$ & 1.0 & 3 & 240 \\
\hline $1.5 \_3 \_240$ & 1.5 & 3 & 240 \\
\hline $2.0 \_3 \_240$ & 2.0 & 3 & 240 \\
\hline $\begin{array}{c}\text { Samples for } \\
\text { Temperature } \\
\text { Model }\end{array}$ & $\begin{array}{c}\mathrm{NaOH} \\
\text { Concentration } \\
\text { (M) }\end{array}$ & $\begin{array}{c}\text { Reaction } \\
\text { Temperature } \\
\left({ }^{\circ} \mathbf{C}\right)\end{array}$ & $\begin{array}{c}\text { Reaction } \\
\text { Time } \\
\text { (Hrs) }\end{array}$ \\
\hline 1.0_3_120 & 1.0 & 3 & 120 \\
\hline $1.0 \_3 \_145$ & 1.0 & 3 & 145 \\
\hline $1.0 \_3 \_170$ & 1.0 & 3 & 170 \\
\hline $1.0 \_3 \_195$ & 1.0 & 3 & 195 \\
\hline $1.0 \_3 \_220$ & 1.0 & 3 & 220 \\
\hline $1.0 \_3 \_240$ & 1.0 & 3 & 240 \\
\hline $\begin{array}{c}\text { Samples } \\
\text { for Time } \\
\text { Model }\end{array}$ & $\begin{array}{c}\mathrm{NaOH} \\
\text { Concentration } \\
(\mathrm{M}) \\
\end{array}$ & $\begin{array}{c}\text { Reaction } \\
\text { Temperature } \\
\left({ }^{\circ} \mathbf{C}\right) \\
\end{array}$ & $\begin{array}{c}\text { Reaction } \\
\text { Time } \\
\text { (Hrs) } \\
\end{array}$ \\
\hline 1.0_1_240 & 1.0 & 1 & 240 \\
\hline 1.0_2_240 & 1.0 & 2 & 240 \\
\hline $1.0 \_3 \_240$ & 1.0 & 3 & 240 \\
\hline $1.0 \_5 \_240$ & 1.0 & 5 & 240 \\
\hline $1.0 \_8 \_240$ & 1.0 & 8 & 240 \\
\hline 1.0_10_240 & 1.0 & 10 & 240 \\
\hline
\end{tabular}

Each parameter in the equation was normalized before completing the regression step, using the following equations:

$$
\begin{aligned}
& C^{*}=\frac{C(\mathrm{M})}{0.1(\mathrm{M})} \\
& T^{*}=\frac{T\left({ }^{\circ} \mathrm{C}\right)}{120\left({ }^{\circ} \mathrm{C}\right)} \\
& t^{*}=\frac{t(\mathrm{Hrs})}{1(\mathrm{Hr})} \\
& h^{*}=\frac{h(\mathrm{~nm})}{\text { Shortest stucture height measured in set }(\mathrm{nm})}
\end{aligned}
$$

where $C$ is $\mathrm{NaOH}$ concentration $(\mathrm{M}), T$ is reaction temperature $\left({ }^{\circ} \mathrm{C}\right)$ and $t$ is reaction time (Hrs). 


\section{Advanced Materials Letters www. vbripress.com/aml}

\section{Results and discussion}

\section{Effect of $\mathrm{NaOH}$ concentration}

SEM images of samples testing the effect of $\mathrm{NaOH}$ concentration can be seen in Fig. 1. The surface morphology of the $\mathrm{TiO}_{2}$ structures show that $\mathrm{NaOH}$ concentration has a profound effect on general surface morphology. Fig. 1 shows that as $\mathrm{NaOH}$ concentration increases, surface morphology changes from small random nanostructures (Fig. 1a and Fig. 1b), to longer pillar-like structures (Fig. 1c and Fig. 1d), and finally to large, interconnected mesh-like structures at high $\mathrm{NaOH}$ concentrations (Fig. 1e and Fig. 1f). The most significant change in morphology occurs between 1.0 and $1.5 \mathrm{M}$ $\mathrm{NaOH}$, where structures change from pillars to a mesh-like array. This change in structure has an associated increase in array height, where structure height increases from $307 \mathrm{~nm}$ (at $1.0 \mathrm{M}$ ) to $880 \mathrm{~nm}($ at $1.5 \mathrm{M}$ ) (Supporting Information, Table 2). Increasing $\mathrm{NaOH}$ concentration leads to the formation of highly dense, close-packed mesh-like structures due to the increased number of nucleation sites at higher $\mathrm{NaOH}$ concentrations. As structures grow, their tips fuse together with neighboring structures $[\mathbf{1 6 , 3 0}]$, thereby creating the highly connected arrays observed.
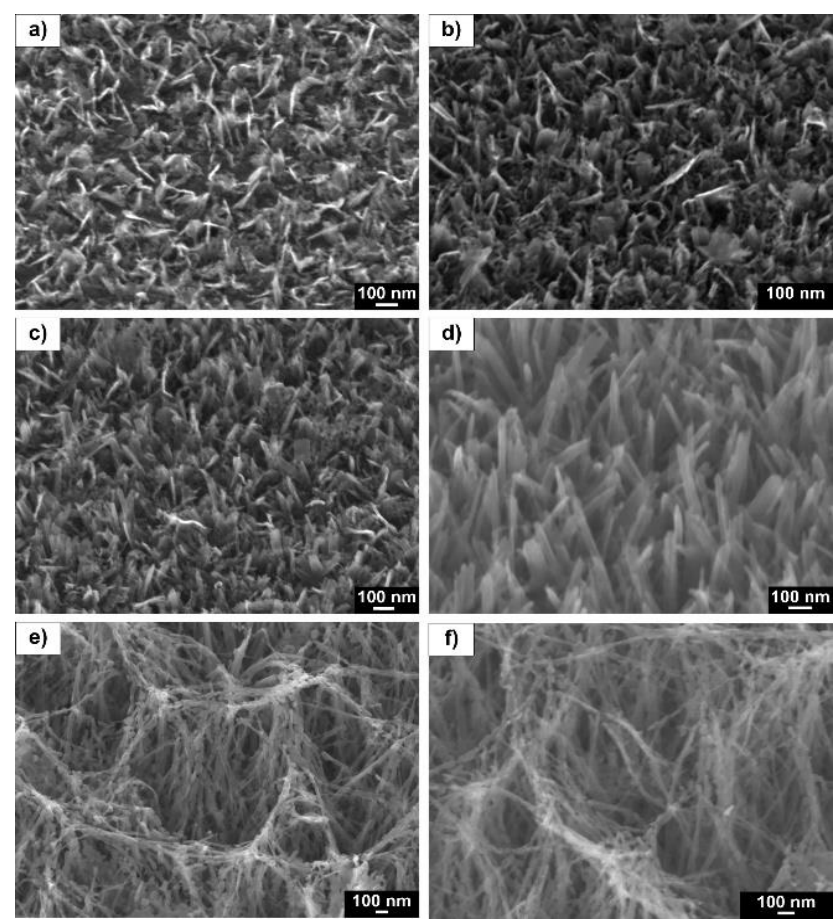

Fig. 1. SEM images of sample a) 0.1_3_240,b) 0.25_3_240, c) 0.5_3_240, d) $1.0 \_3 \_240$, e) $1.5 \_3 \_240$ and f) $2.0 \_3 \_240$

The first step of modelling the effect of $\mathrm{NaOH}$ concentration on structure height was to explore the data in IBM SPSS Statistics. Fig. 2a shows that structure height generally increases with $\mathrm{NaOH}$ concentration. At small $\mathrm{NaOH}$ concentrations $(0.1 \mathrm{M})$ the range of nanostructure height is much smaller, whereas at the highest concentration $(2.0 \mathrm{M})$, there is a larger range of height recorded.
A quadratic curve was found to be the best estimation of the data, hence the model is in the general quadratic form $y=a x^{2}+b x+c$, where $a, b$ and $c$ are parameter coefficients, $x$ is the normalized $\mathrm{NaOH}$ concentration and $y$ is the normalized array height. Using this general form, parameter estimates were computed in SPSS and the following equation obtained:

$$
h^{*}=0.031 C^{* 2}-0.140 C^{*}+1.838
$$

where $h^{*}$ is normalized average structure height $\left(h^{*}=h / 120 \mathrm{~nm}\right)$ and $C^{*}$ is normalized $\mathrm{NaOH}$ concentration.
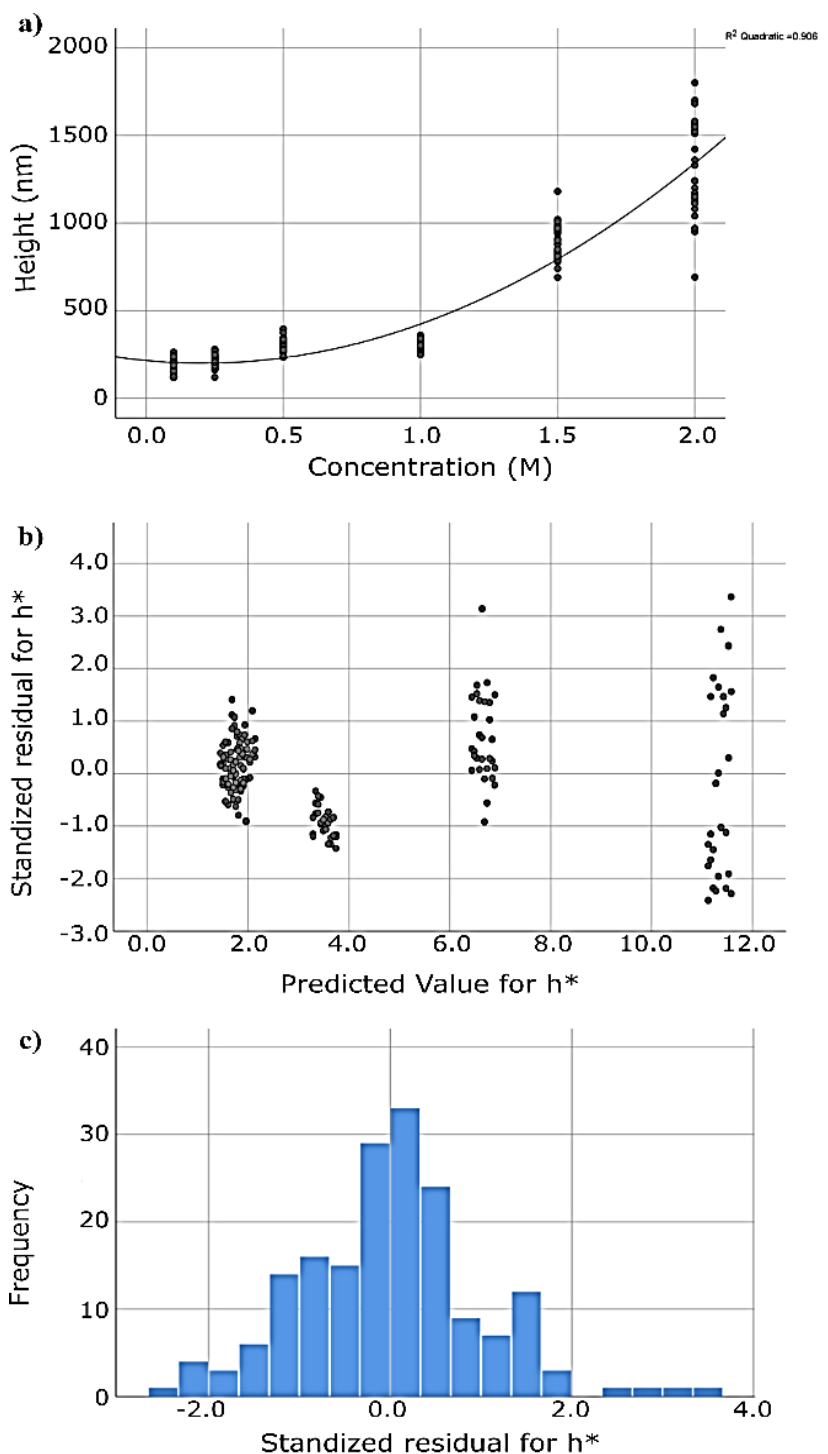

Fig. 2. (a) Change in structure height ( $\mathrm{nm}$ ) with $\mathrm{NaOH}$ concentration, (b) model residual scatterplot, (c) standardized residual normality plot.

The residual data (Fig. 2b and Fig. 2c) examines the statistical accuracy of the model. The scatterplot of the standardised residuals versus the predicted value for normalized height (Fig. 2b) shows that residual values are fairly random but are grouped more closely at smaller heights than at larger heights, showing uneven homoscedasticity (a measure of the homogeneity of the model's variance). The range of residual values is small at 


\section{Advanced Materials Letters www. vbripress.com/aml}

lower predicted height values and increases at higher predicted heights. This indicates that at small concentrations the model is more accurate compared to larger $\mathrm{NaOH}$ concentrations. This is to be expected, given the large variance observed in Fig. 2a, where the range of height values is much larger at higher concentrations.

Fig. 2c shows the residual normality of the predicted model has a general bell curve shape. The skewness $(0.280)$ and kurtosis of the residual normality were found to be 0.280 and 0.861 and are within the acceptable range of \pm 3.0. The mean (0.000) and median (0.0127) of the residual data are similar, reinforcing the legitimacy of the model. Therefore, the model is valid for predicting nanostructure height using $\mathrm{NaOH}$ concentration at constant reaction temperature of $240^{\circ} \mathrm{C}$ and 3 hours reaction time.

\section{Effect of reaction temperature}

Fig. 3 shows the change in structure, size and morphology of the hydrothermally synthesized $\mathrm{TiO}_{2}$ with reaction temperature.
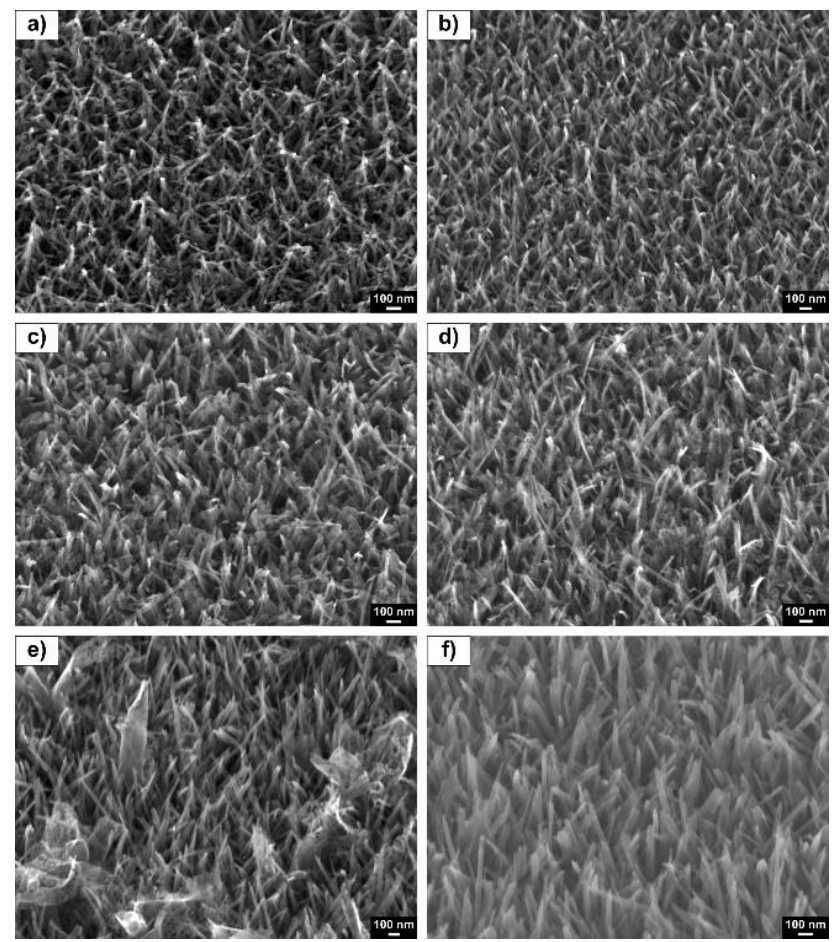

Fig. 3. SEM images of sample a) 1.0_3_120, b) 1.0_3_145, c) 1.0_3_170, d) $1.0 \_3 \_195$, e) $1.0 \_3 \_220$ and f) $1.0 \_3 \_240$.

Fig. 3 shows that hydrothermal temperature has a conservative effect on surface morphology. At $120^{\circ} \mathrm{C}$ structures appear to be fused at the tip [31], which separate as temperature increases, becoming individualized. The change in morphology is less obvious compared to morphology changes with $\mathrm{NaOH}$ concentration.

To form the model relating height to reaction temperature, $\mathrm{NaOH}$ concentration remained constant at 1.0 $\mathrm{M}$, and reaction time at 3 hours. Fig. 4a shows the scatterplot of the change in array height with increasing hydrothermal temperature.

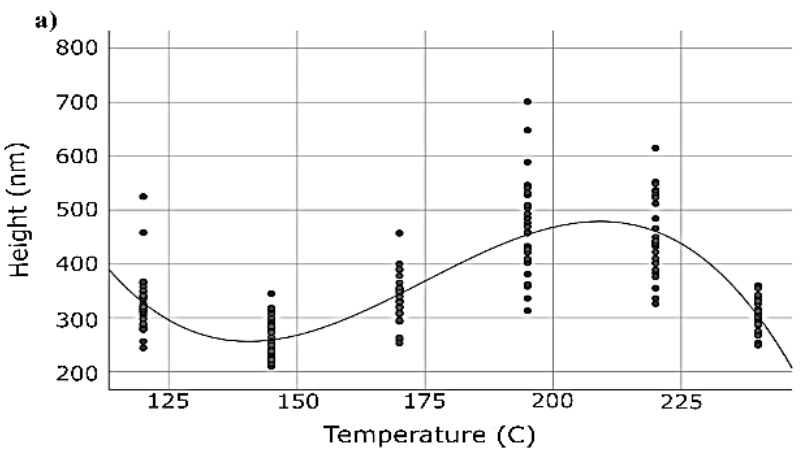

b)

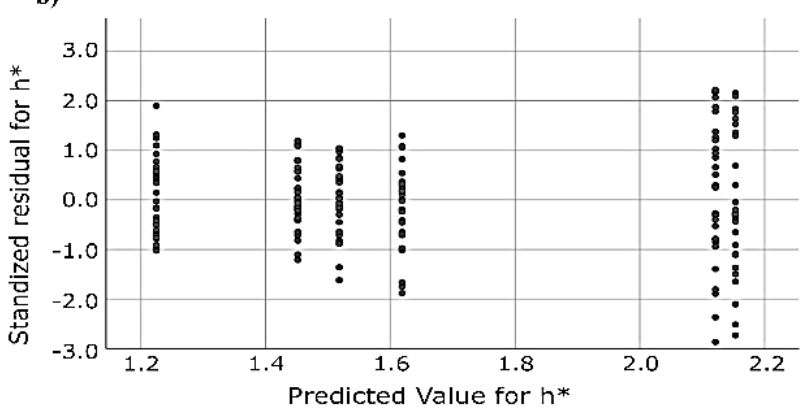

c)

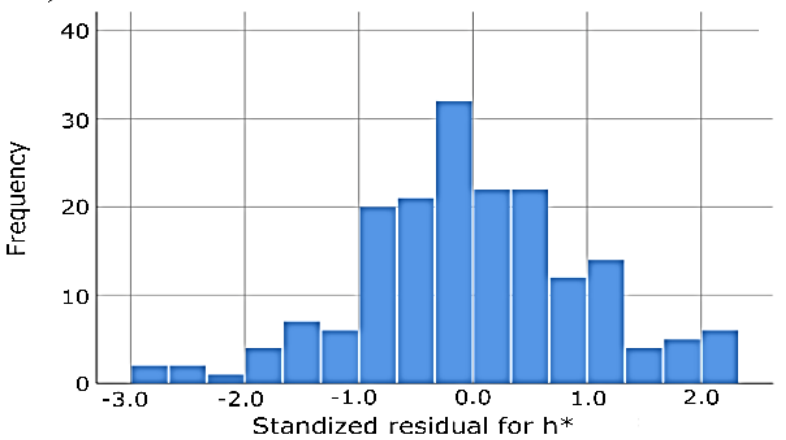

Fig. 4. (a) Change in nanostructure height $(\mathrm{nm})$ with hydrothermal temperature $\left({ }^{\circ} \mathrm{C}\right.$ ), (b) residual scatterplot, (c) standardized residual normality plot.

Fig. 4a shows that the height follows a general cubic relationship with reaction temperature. The following equation was developed in IBM SPSS Statistics to describe the relationship between structure height and hydrothermal reaction time:

$$
h^{*}=-10.666 T^{* 3}-46.580 T^{* 2}-65.144 T^{*}+30.749
$$

where $h^{*}$ is the normalized structure height $\left(h^{*}=h / 210 \mathrm{~nm}\right)$ and $T^{*}$ is normalized hydrothermal reaction temperature. This model shows that structure height is predicted to initially decrease with increasing temperature until approximately $140^{\circ} \mathrm{C}(1.17$ normalized temperature $)$, after which height increases with temperature until approximately $215^{\circ} \mathrm{C}(1.79$ normalized temperature). After this temperature, height once again decreases with increasing temperature until $240^{\circ} \mathrm{C} \quad(2.0$ normalized temperature).

Fig. 4b shows that the residuals are random, with no obvious pattern and a reasonable level of homoscedasticity. The normality plot of the residuals (Fig. 4c) shows an obvious bell curve shape, indicating that the model has a 


\section{Advanced Materials Letters www. vbripress.com/aml}

high level of accuracy. The kurtosis (0.270) and skewness $(-0.099)$ also show that the residual normality is favorable. Therefore, the model is statistically valid for predicting nanostructure height using hydrothermal reaction temperature at constant $\mathrm{NaOH}$ concentration $(1.0 \mathrm{M})$ and 3 hours reaction time.

\section{Effect of reaction time}

Fig. 5 shows change in surface morphology with increasing hydrothermal reaction time.
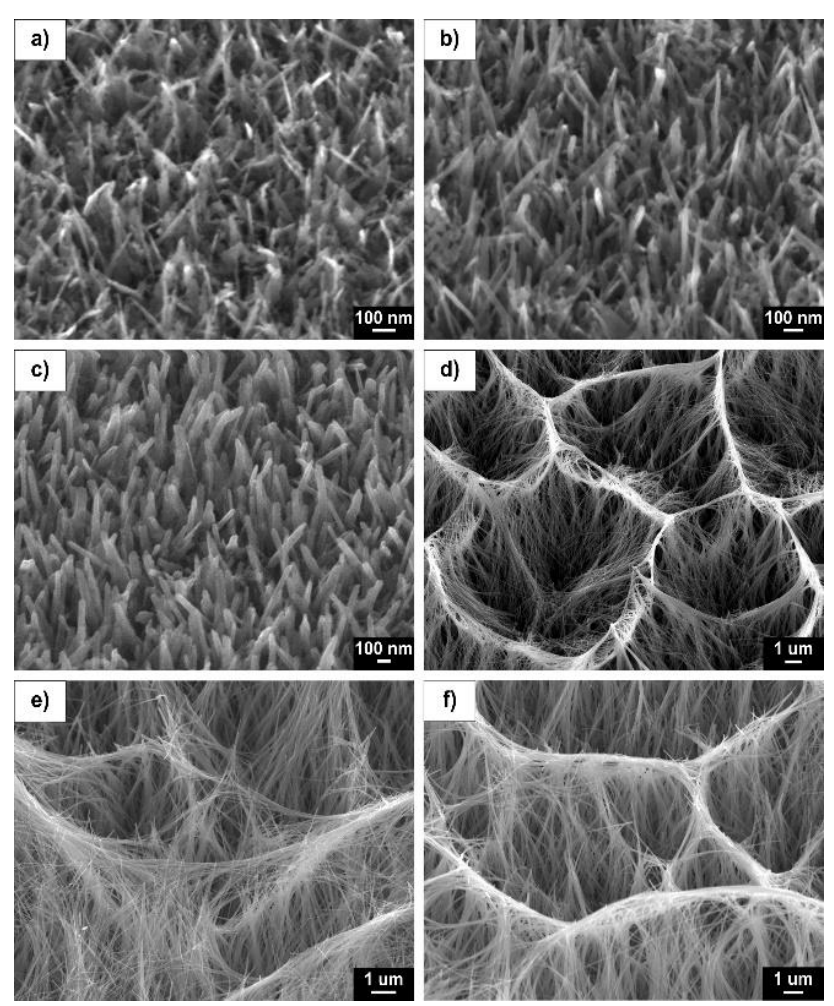

Fig. 5. SEM images of samples (a) 1.0_1_240, b) 1.0_2_240, (c) $1.0 \_3 \_240$, (d) $1.0 \_5 \_240$, (e) $1.0 \_8 \_240$ and (f) $1.0 \_10 \_240$.

It is interesting to note that as time increases, structures grow from individualized pillar-like structures (Fig. 5a Fig. 5c) to a mesh-like array (Fig. 5d - Fig. 5f). There is a sharp and significant increase in structure height between 3 and 5 hours. During this time, structures grow from nanoscale to microscale structures, however structure diameter shows little change. The largest array height occurs at 1.0_8_240 $(7337 \mathrm{~nm})$. Array height then decreases to $6884 \mathrm{~nm}$ after 10 hours (Supplementary Information, Table 2). Fig. 6a shows that for reaction times between 1 to 3 hours, structures have a comparatively small mean height. Structure heights at the first three reaction times are similar, showing that during this time-period, there is little change in height with temperature. At the higher tested reaction times (5, 8 and 10 hours), structure height increases significantly compared to the 1 to 3 -hour time conditions. Interestingly, for the three shorter reaction times, there is little variation in structure height of these samples. However, the three longer reaction times produce a large range of variation in height. a)

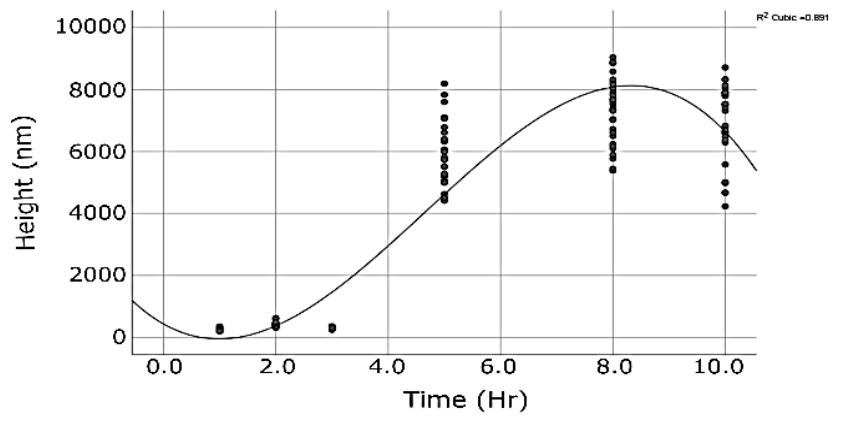

b)

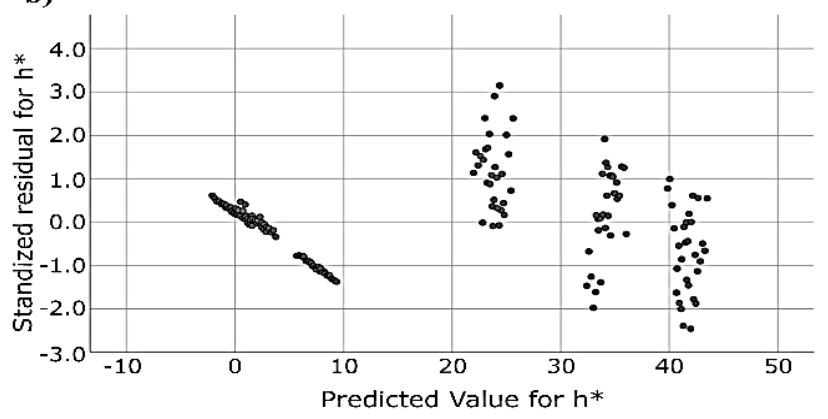

c)

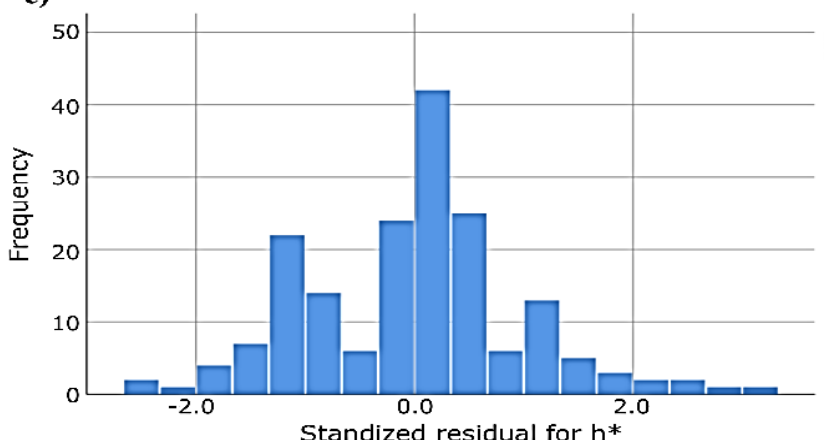

Fig. 6. (a) Change in height ( $\mathrm{nm}$ ) with hydrothermal reaction time (Hrs), (b) residual scatterplot, (c) standardized residual normality plot.

A model describing the change in nanostructure height with reaction time was developed in IBM SPSS Statistics, and found to be:

$$
h^{*}=-0.214^{* 3}+2.987 t^{* 2}-5.275 t^{*}-0.681
$$

where $h^{*}$ is the normalized average array height $\left(h^{*}=h / 194\right.$ $\mathrm{nm})$ and $t^{*}$ is hydrothermal reaction time. Fig. $6 \mathbf{b}$ and Fig. 6c show random residuals as well as a satisfactory normality bell curve. The model is valid for hydrothermal reaction times between 1 and 10 hours, at a reaction temperature of $240^{\circ} \mathrm{C}$ and reacting with $1.0 \mathrm{M} \mathrm{NaOH}$.

\section{Limitations}

While these models are a reasonable starting point for modelling the effect of hydrothermal process parameters on resulting structure height, there are several ways in which the models could be improved. Firstly, and most significantly, the models only show the individual effect of each process parameter. From this point, our current work will involve combining these models to find a single expression for nanostructure height, as a function of $\mathrm{NaOH}$ concentration, reaction time and reaction temperature. 


\section{Advanced Materials Letters www. vbripress.com/aml}

A significant drawback of this model is the relatively small data set. Ideally, at least 100 experimental conditions would be used to construct the statistical models, allowing for much more accurate models to be developed. Another drawback is that the process used to develop the models ignores the fact that the 30 height measurements are taken from 3 samples, treating the data as 30 independent samples. However, this limitation is partially adjusted for by including the sample and replicate number as fixed factors in the univariate general model construction.

Another limitation is that the model is only valid within the tested parameter bounds, i.e. between 0.1 and $1.0 \mathrm{M}$ $\mathrm{NaOH}, 1$ and 10 hours, and 120 and $240^{\circ} \mathrm{C}$, and has not yet been experimentally validated. While the models have some real-world limitations, they serve as estimate for nanostructure height given specified process variables. The models are applicable for predicting the height of the surface structures in a hydrothermal experiment, where Ti is reacted with $\mathrm{NaOH}$ to form $\mathrm{TiO}_{2}$.

\section{Conclusion}

This work developed models to predict structure height of hydrothermally synthesized $\mathrm{TiO}_{2}$ nanostructures from three experimental parameters: $\mathrm{NaOH}$ concentration, reaction time and reaction temperature. All models were qualitatively validated using statistical analysis. These models can be employed by those using the hydrothermal process to predict structure morphology before beginning experimental work. The future work of this study is to develop a single model predicting nanostructure height as a function of $\mathrm{NaOH}$ concentration, reaction time and reaction temperature.

\section{Acknowledgements}

This research was supported by the Queensland University of Technology, through the Research Training Program (RTP) Stipend. This research was also funded by the Australian Research Council (ARC) Discovery Grant (DP180101098) for the project "Antibacterial Impact Assessment of Nanopillar Surfaces on Titanium Implants". The authors would like to thank Dotmar Engineering Plastic Products (Brisbane), the Central Analytical Research Facility (CARF QUT), Design and Manufacturing Centre (DMC QUT), Institute for Future Environments (IFE QUT), the Institute of Health and Biomedical Innovation (IHBI QUT) and the Translational Research Institute Australia (TRI).

\section{Author's contributions}

Conceived the plan: PY; Performed the expeirments: AJ; Data analysis: AJ; Wrote the paper: AJ; Reviewed and approved manuscript: PY. Authors have no competing financial interests.

\section{Keywords}

Hydrothermal synthesis, titanium dioxide nanostructures, bactericidal surfaces, hydrothermal growth models.

Received: 19 November 2019

Revised: 11 December 2019

Accepted: 23 December 2019

\section{References}

1. Hasan, J.; Webb, H.K.; Truong, V.K.; Pogodin, S.; Baulin, V.A.; Watson, G.S.; Watson, J.A.; Crawford, R.J.; Ivanova, E.P.; Appl. Microbiol. Biotechnol.; 2013, 97, 9257.
2. Pogodin, S.; Hasan, J.; Baulin, V.A.; Webb, H.K.; Truong, V.K.; Phong Nguyen, T.H.; Boshkovikj, V.; Fluke, C.J.; Watson, G.S.; Watson, J.A.; Crawford, R.J.; Ivanova, E.P.; Biophys. J.; 2013, 104, 835 .

3. Bandara, C.D.; Singh, S.; Afara, I.O.; Wolff, A.; Tesfamichael, T.; Ostrikov, K.; Oloyede, A.; ACS Appl. Mater. Interfaces; 2017, 9, 6746.

4. Balčytis, A.; Seniutinas, G.; Lapierre, F.; Juodkazis, S.; Artificial antibacterial surfaces that are simple to fabricate, in: E.P. Ivanova, R.J. Crawford (Eds.), Antibacterial Surfaces, Springer International Publishing, Cham, 2015, pp. 27-40.

5. Ensikat, H.J.; Ditsche-Kuru, P.; Neinhuis, C.; Barthlott, W.; Beilstein J. Nanotechnol.; 2011, 2, 152.

6. Yan, Y.Y.; Gao, N.; Barthlott, W.; Adv. Colloid Interface Sci.; 2011, $169,80$.

7. Zhang, C.; McAdams, D.A.; Grunlan, J.C.; Adv. Mater.; 2016, 28, 6292.

8. Diu, T.; Faruqui, N.; Sjostrom, T.; Lamarre, B.; Jenkinson, H.F.; Su, B.; Ryadnov, M.G.; Sci. Rep.; 2014, 4, 7122.

9. Hasan, J.; Chatterjee, K.; Nanoscale; 2015, 7, 15568.

10. Hasan, J.; Crawford, R.J.; Ivanova, E.P.; Trends Biotechnol.; 2013, $31,295$.

11. Ivanova, E.P.; Hasan, J.; Webb, H.K.; Truong, V.K.; Watson, G.S.; Watson, J.A.; Baulin, V.A.; Pogodin, S.; Wang, J.Y.; Tobin, M.J.; Löbbe, C.; Crawford, R.J.; Small; 2012, 8, 2489.

12. Zhang,G.; Zhang, J.; Xie, G.; Liu, Z.; Shao, H.; Small; 2006, 2, 1440.

13. Bhadra, C.M.; Truong, V.K.; Pham, V.T.H.; Al Kobaisi, M.; Seniutinas, G.; Wang, J.Y.; Juodkazis, S.; Crawford, R.J.; Ivanova, E.P.; Sci. Rep.; 2015, 5, 16817.

14. Dickson, M.N.; Liang, E.I.; Rodriguez, L.A.; Vollereaux, N.; Yee, A.F.; Biointerphases; 2015, 10, 021010.

15. Linklater, D.P.; Nguyen, H.K.D.; Bhadra, C.M.; Juodkazis, S.; Ivanova, E.P.; Nanotechnology; 2017, 28, 9.

16. Jaggessar, A.; Mathew, A.; Wang, H.; Tesfamichael, T.; Yan, C.; Yarlagadda, P.K.D.V.; J. Mech. Behav. Biomed. Mater.; 2018, 80, 311 .

17. Zhu, K.X.; Hu, G.X.; J. Supercrit Fluids; 2014, 94, 165

18. Hasan, J.; Raj, S.; Yadav, L.; Chatterjee, K.; RSC Adv.; 2015, 5, 44953.

19. Alves, N.M.; Shi, J.; Oramas, E.; Santos, J.L.; Tomás, H.; Mano, J.F.; J. Biomed. Mater. Res. A; 2009, 91, 480.

20. Privett, B.J.; Youn, J.; Hong, S.A.; Lee, J.; Han, J.; Shin, J.H.; Schoenfisch, M.H.; Langmuir; 2011, 27, 9597.

21. Bhadra, C.; Werner, M.; Baulin, V.A.; Truong, V.; Kobaisi, M.; Nguyen, S.; Balcytis, A.; Juodkazis, S.; Wang, J.; Mainwaring, D.; Crawford, R.; Ivanova, E.; Nano-Micro Letters; 2018, 10, 1.

22. Velic, A.; Tesfamichael, T.; Li, Z.; Yarlagadda, P.K.D.V.; Procedia Manufacturing; 2019, 30, 514.

23. Velic, A.; Mathew, A.; Hines, P.; Yarlagadda, P.K.D.V.; Journal of the Mechanical Behavior of Biomedical Materials; 2019, 91, 416.

24. Jaggessar, A.; Mathew, A.; Tesfamichael, T.; Wang, H.; Yan, C.; Yarlagadda, P.K.; Molecules; 2019, 24, 1201.

25. Lorenzetti, M.; Dogsa, I.; Stosicki, T.; Stopar, D.; Kalin, M.; Kobe, S.; Novak, S.; ACS Appl. Mater. Interfaces; 2015, 7, 1644.

26. Chen, X.; Mao, S.S.; Chem. Rev.; 2007, 107, 2891.

27. Oh, J.K.; Lee, J.K.; Kim, S.J.; Park, K.W.; J. Ind. Eng. Chem.; 2009, $15,270$.

28. Cui, Z.; Yang, H.; Wang, B.; Li, R.; Wang, X.; Nanoscale Research Letters; 2016, 11, 190.

29. Wang, M.D.; Xing, C.C.; Cao, K.; Meng, L.; Liu, J.B.; J. Phys. Chem. Solids; 2014, 75, 808.

30. Liu, B.; Aydil, E.S.; J. Am. Chem. Soc.; 2009, 131, 3985.

31. Ozel, F.; Kockar, H.; Karaagac, O.; J. Supercond Nov. Magn.; 2015, 28,823 .

32. Łencka, M.M.; Riman, R.E.; Chem. Mater.; 1993, 5, 61.

33. Dias, A.; J. Solution Chem.; 2011, 40, 1126.

34. Cho, S.B.; Noh, J.S.; Lencka, M.M.; Riman, R.E.; J. Eur. Ceram. Soc.; 2003, 23, 2323

35. Byrappa, K.; Yoshimura, M.; Handbook of Hydrothermal Technology, William Andrew, Norwich, N.Y, 2013. 